\title{
TREATMENT OF MEDIAL CONDYLE FRACTURES OF HUMERUS IN ADULTS - A CASE SERIES
}

\author{
T. Bhattacharya ${ }^{1}$, H. C. Frank 2 , K. Hazarika 3 , T. Bharali', S. Mittal ${ }^{5}$
}

1 Professor, Department of Orthopaedics, Gauhati Medical College.

${ }^{2}$ Associate Professor, Department of Orthopaedics, Gauhati Medical College

${ }^{3}$ Registrar, Department of Orthopaedics, Gauhati Medical College.

${ }^{4}$ Registrar, Department of Orthopaedics, Gauhati Medical College.

5Postgraduate Student, Department of Orthopaedics, Gauhati Medical College.

\section{ABSTRACT}

\section{BACKGROUND}

Fracture of the medial condyle of humerus is very rare. Only a few reports are available where this injury is seen after closure of the condylar and medial epicondylar apophyses.

The aim of this study is 1) To highlight the rarity of this fracture in adult population. 2) To report the clinical \& radiological outcome following internal fixation.

\section{MATERIALS AND METHODS}

Over a period of 6 years (2005-2011), 6 medial condyle humeral fractures in adults were seen in Orthopaedics Department, Gauhati Medical College and Hospital. Surgical fixation by open reduction and internal fixation was done with cancellous screws and/or Recon plates and additional K-wires whenever required. The patients were followed up and were evaluated clinically, radiologically and functionally (using Mayo Elbow Performance Score).

\section{RESULTS}

All the 6 cases united clinicoradiologically. Based on the clinical criteria for evaluation of results, excellent results were obtained in 4 cases and good result in 2 cases. None of the cases reported with ulnar nerve injury.

\section{DISCUSSION}

Isolated fractures of medial condyle of the humerus in adults are rare injuries. The ideal management of these fractures when seen without any delay aims at achieving anatomic reduction and stable fixation followed by early range of motion exercises for the elbow. Few studies have been done on internal fixation of this fracture. Similar to other studies, we obtained excellent and good results in all the cases.

\section{CONCLUSION}

Fixation with cancellous screws, and/or recon-plate is effective method of rigid fixation to achieve good to excellent results in medial condyle fracture of humerus.

\section{KEYWORDS}

Medial Epicondyle Humerus, Milch Classification, Anatomical Reduction.

HOW TO CITE THIS ARTICLE: Bhattacharya T, Frank HC, Hazarika K et al. Treatment of medial condyle fractures of humerus in adults - A case series. J. Evolution Med. Dent. Sci. 2017;6(10):804-807, DOI: 10.14260/Jemds/2017/174

\section{BACKGROUND}

Fracture of the medial condyle of humerus is very rare, the incidence being less than $1-2 \%$ of all elbow injuries. It has even been described by some as a fracture that is seen "once in a lifetime".(1) Most reports focus on this fracture in the paediatric age group where it occurs more frequently.(2) Only a few reports are available where this injury is seen after closure of the condylar and medial epicondylar apophyses. ${ }^{3,4)}$ There is an almost equal gender distribution. They are most commonly produced either from falls onto the outstretched hand or onto the flexed elbow, although a significant proportion of high-energy injuries also occur.

Financial or Other, Competing Interest: None.

Submission 29-11-2016, Peer Review 19-01-2017,

Acceptance 25-01-2017, Published 02-02-2017.

Corresponding Author:

Dr. Kishore Hazarika,

C/o. Kumud, Ch. Bharali, House No.-5,

Milijulipath, Near Hostel No.4 GMCH,

Rupnagar East

Guwahati-32, Assam.

E-mail: k,hazarika90@gmail.com

DOI: $10.14260 /$ jemds $/ 2017 / 174$

\section{(c) $(\mathbf{1}) \ominus$}

Various forms of management ranging from splints, POP casts, fixation with screws and plates, to excision of the fragment are practised. The aims of this study were 1) To highlight the rarity of this fracture in adult population. 2) To report the clinical \& radiological outcome following internal fixation.

\section{MATERIALS AND METHODS}

Over a period of 6 years (2005-2011), 6 medial condyle humeral fractures in adults were seen in Orthopaedics Department, Gauhati Medical College and Hospital.

4 patients were male and 2 were female with ages ranging from 23 to 50 years (mean age - 35.5 years). The duration between injury and reporting to our centre ranged from 1 day to 10 days (mean - 4 days). The mode of injury was RTA in 4 cases, physical assault in 1 and fall in 1 case. 4 cases were Milch type II and 2 were Milch type I fractures. All the 6 cases were closed fractures without any neurovascular injury or any ipsilateral limb or other associated injuries. Required workup was done, informed consent was taken and surgical fixation by open reduction and internal fixation was done with cancellous screws and/or recon-plates and additional Kwires whenever required. In the post-operative period, the 
limb was immobilised in a POP slab for 3 weeks after which active elbow mobilisation exercises were started. The patients were followed up and were evaluated clinically, radiologically and functionally (Using Mayo Elbow Performance Score).
The followup ranged from 12 months to 60 months (mean 38 months) - Table 1 . The results were evaluated on the basis of clinical criteria and were classified as excellent, good, fair or poor considering Mayo Elbow Performance Score.

\section{RESULTS}

\begin{tabular}{|c|c|c|c|c|c|c|c|c|c|c|}
\hline Sl. No. & Name & Age/Sex & Type & $\begin{array}{c}\text { Mechanism } \\
\text { of Injury }\end{array}$ & $\begin{array}{c}\text { Period of } \\
\text { Delay }\end{array}$ & Pain & $\begin{array}{c}\text { Motion } \\
\text { Arc }\end{array}$ & Stability & Function & Followup \\
\hline 1 & C.D. & $42 / \mathrm{M}$ & Milch II & RTA & 5 days & NONE & $>100^{\circ}$ & Stable & Excellent & 4 years \\
\hline 2 & Z.I. & $34 / \mathrm{M}$ & Milch II & RTA & 2 days & NONE & $>100^{\circ}$ & Stable & Excellent & 3 years \\
\hline 3 & F.C. & $38 / \mathrm{M}$ & Milch I & RTA & 1 day & NONE & $>100^{\circ}$ & Stable & Excellent & 5 years \\
\hline 4 & N.B. & $23 / \mathrm{M}$ & Milch II & ASSAULT & 10 days & MILD & $50-100^{\circ}$ & $\begin{array}{c}\text { Moderate } \\
\text { Instability }\end{array}$ & Good & 4 years \\
\hline 5 & P.S. & $50 / \mathrm{F}$ & Milch I & FALL & 2 days & NONE & $50-100^{\circ}$ & Stable & Good & 2 years \\
\hline 6 & S.D. & $26 / \mathrm{F}$ & Milch II & RTA & 4 days & NONE & $>100^{\circ}$ & Stable & Excellent & 1 year \\
\hline & \multicolumn{7}{|c|}{ Table 1 } \\
\hline
\end{tabular}

All the 6 cases united clinicoradiologically, ranging from 90 days to 134 days (mean - 112 days). 5 patients had no pain, and 1 patient had mild pain. 4 cases had motion arc $>100^{\circ}, 2$ cases had motion arc 50-100 .5 cases had good stability, and 1 case had moderate instability. Based on the clinical criteria for evaluation of results, excellent results were obtained in 4 cases and good result in 2 cases. None of the cases reported with ulnar nerve injury.

\section{Minimal Fixation with Cancellous Screw and K Wire}

\section{Pre-operative}
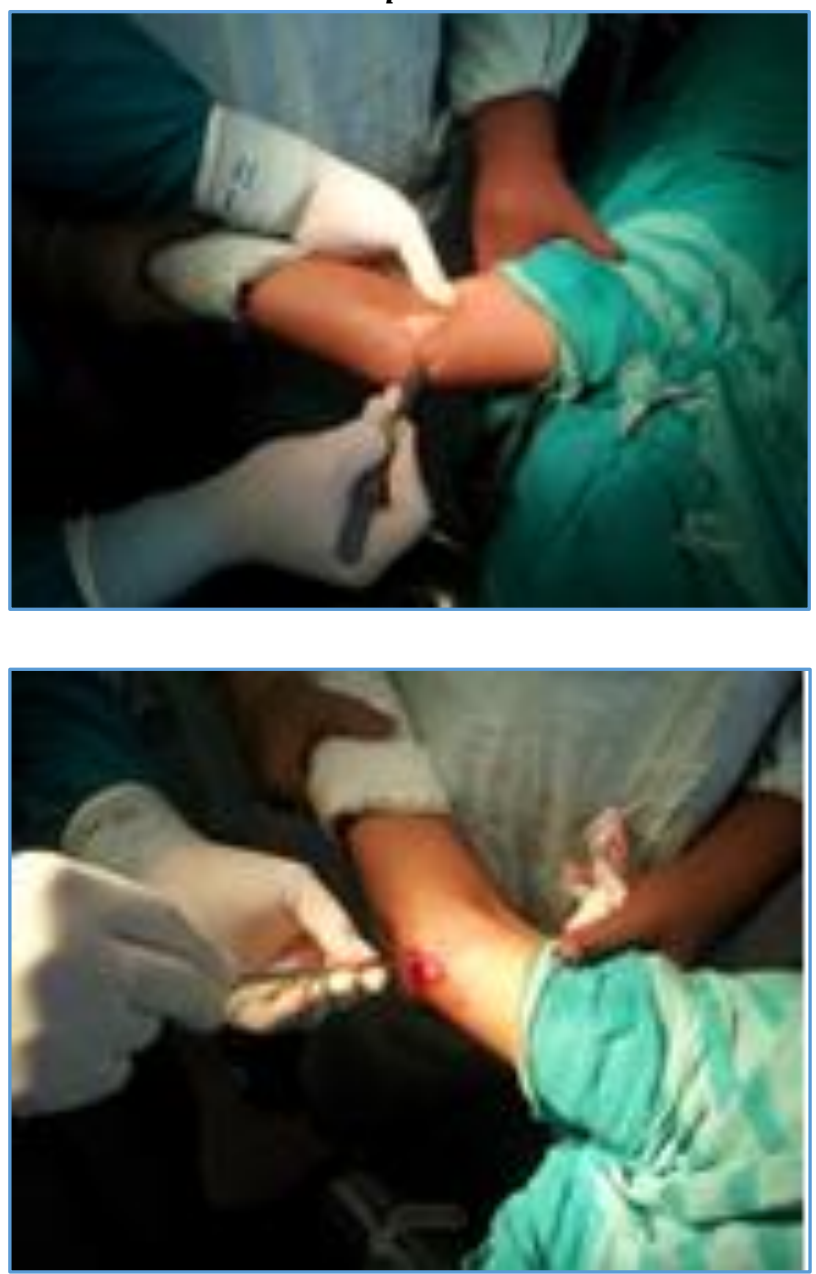
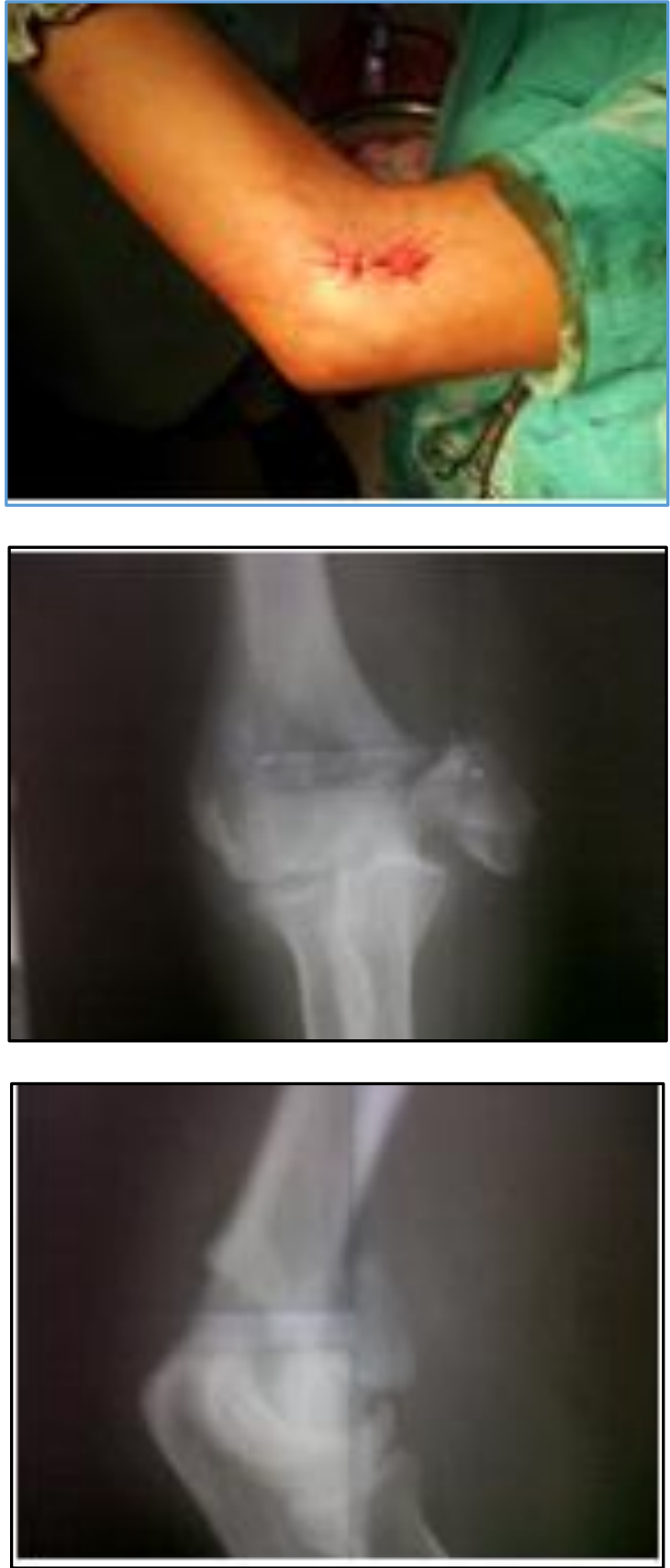


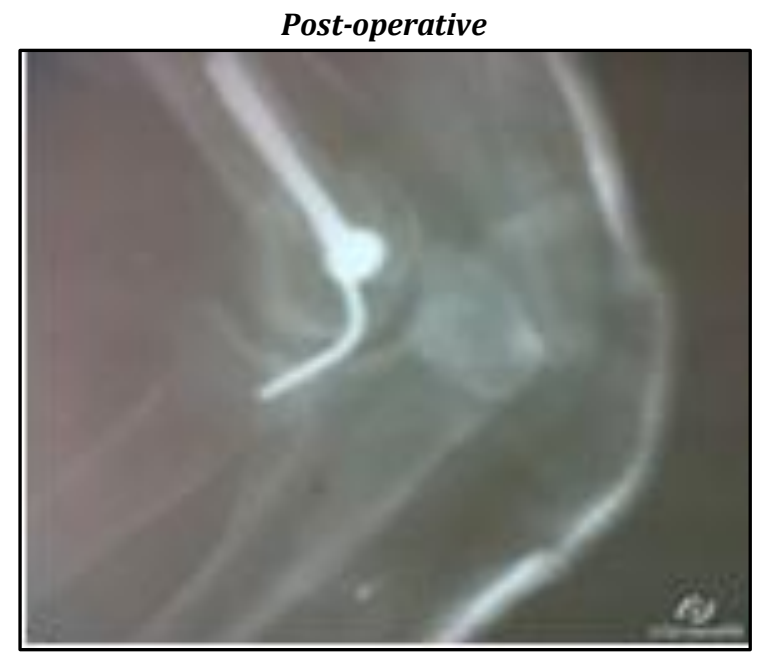

\section{Fixation with Recon Plate and Cancellous Screw}
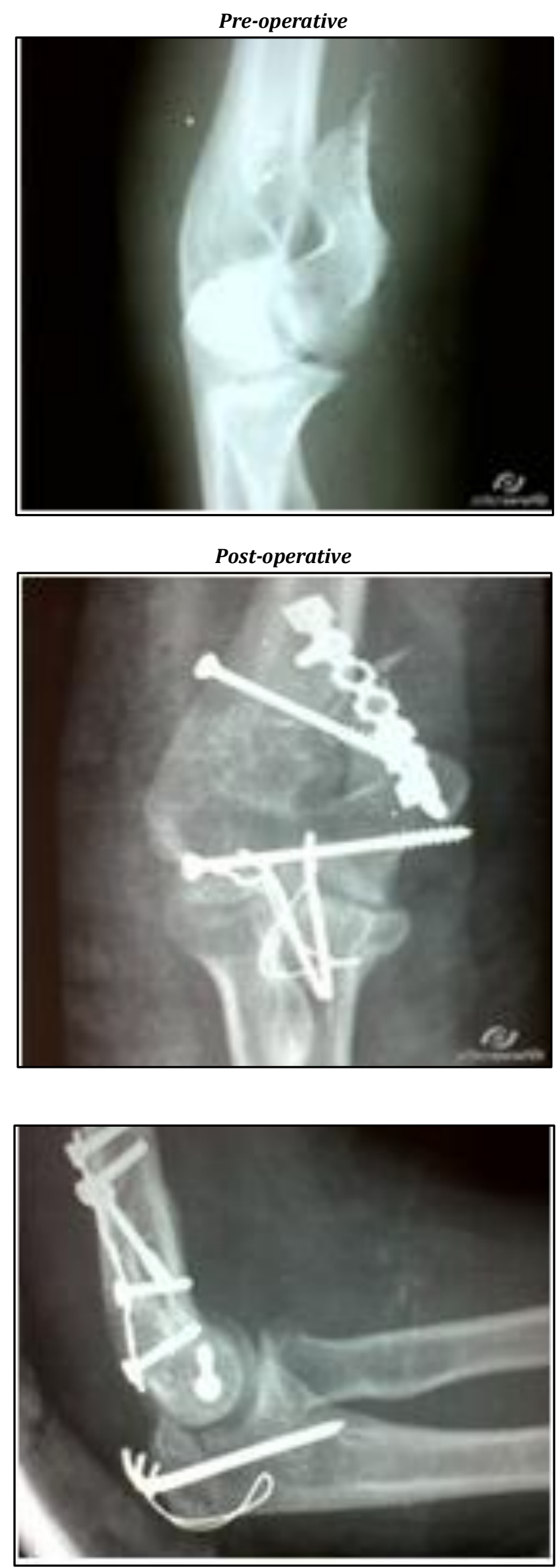

\section{Post-operative}

\section{Clinical Photographs}
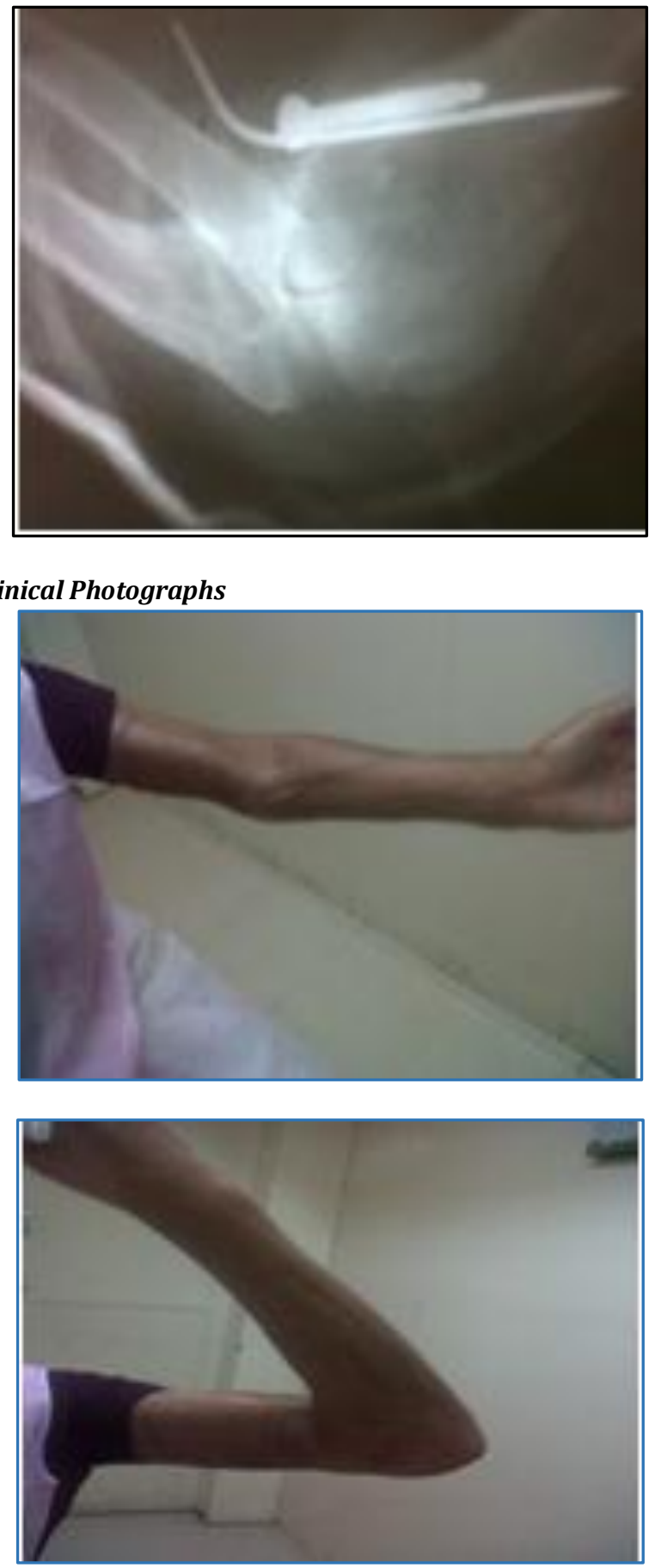


\section{Clinical Photographs}
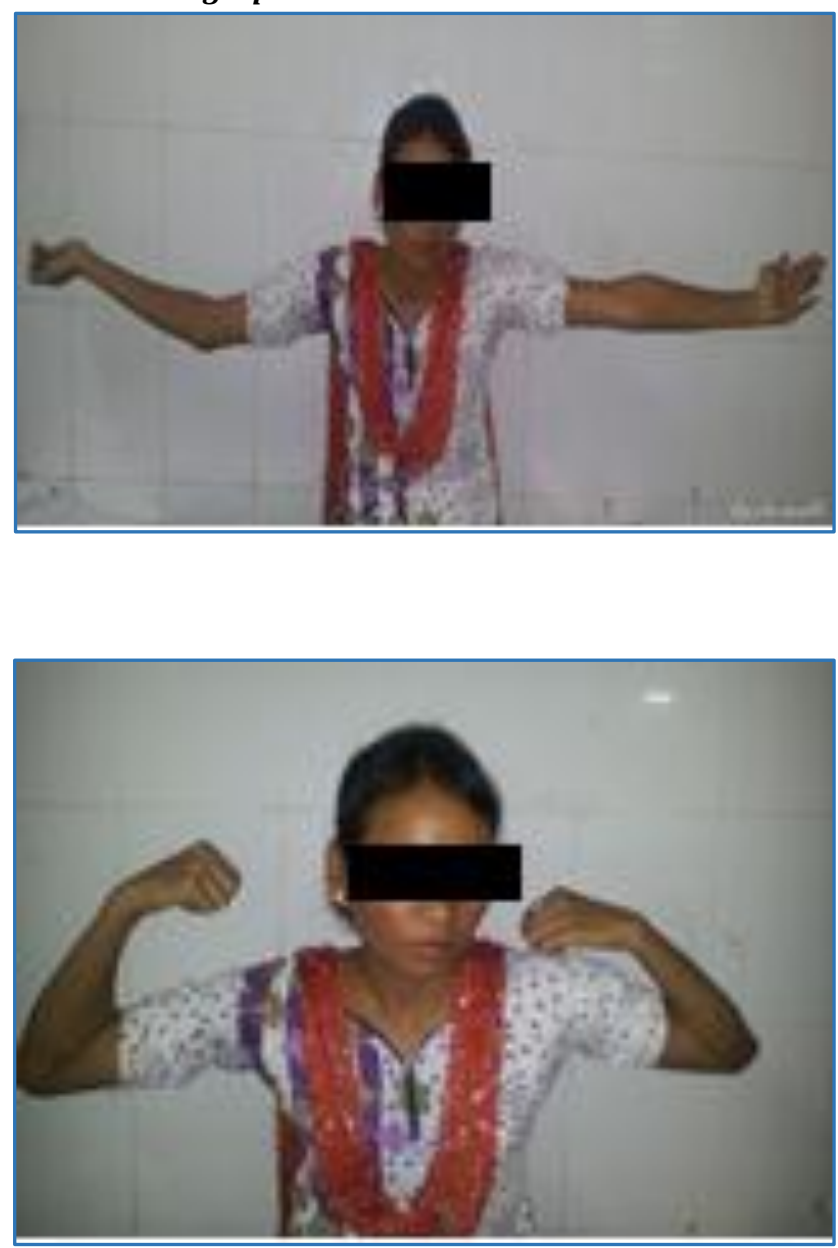

\section{DISCUSSION}

Isolated fractures of medial condyle of the humerus in adults are rare injuries. Fractures of the medial condyle occur due to abduction forces directed at right angles to the longitudinal axis of the extended elbow. Such forces may eventuate in two different types of fractures, which are (1) an avulsion type of injury with downward displacement of the fractured condyle and (2) a compression type of fracture with upward displacement of the fractured condyles.(5) Two types exist Milch type I and II.(5) In Milch type I fractures the injury mechanism is such that the lateral trochlear ridge is left intact with the main humeral shaft; in Milch type II, this ridge is a part of the fractured condylar fragment. The ideal management of these fractures when seen without any delay, aims at achieving anatomic reduction and stable fixation followed by early range of motion exercises for the elbow.

\begin{tabular}{|c|c|c|c|c|c|c|}
\hline $\begin{array}{l}\text { Sl. } \\
\text { No. }\end{array}$ & Study & Year & $\begin{array}{l}\text { No. of } \\
\text { Cases }\end{array}$ & \begin{tabular}{|r|} 
Type of \\
$\#$ (Milch)
\end{tabular} & $\begin{array}{l}\text { Method of } \\
\text { Fixation }\end{array}$ & Results \\
\hline 1 & $\begin{array}{l}\text { Aitken } \\
\text { et al. }\end{array}$ & 1986 & 2 & NA & ORIF & Good \\
\hline 2 & $\begin{array}{l}\text { Jupiter } \\
\text { et al. }\end{array}$ & 1988 & 5 & II & & \begin{tabular}{|c} 
Good/ \\
Excellent \\
4 \\
Poor 1
\end{tabular} \\
\hline 3 & $\begin{array}{l}\text { Behrman } \\
\text { \&Shelton }\end{array}$ & 1990 & 1 & II & $\begin{array}{l}\text { ORIF with } \\
\text { OA screws }\end{array}$ & Good \\
\hline 4 & $\begin{array}{l}\text { O N Nagi } \\
\text { et al. }\end{array}$ & 2000 & 7 & I & $\begin{array}{c}4 \text { ORIF } \\
2 \text { Excision } \\
1 \text { Non-op }\end{array}$ & \begin{tabular}{|c} 
Good/ \\
Excellent \\
6 \\
Poor 1
\end{tabular} \\
\hline 5 & $\begin{array}{l}\text { Current } \\
\text { study }\end{array}$ & 2012 & 6 & I -2, II- 4 & $\begin{array}{l}\text { ORIF with } \\
\text { Cancellous } \\
\text { screws } \\
\text { and/or } \\
\text { recon-plate }\end{array}$ & $\begin{array}{c}\text { Good/ } \\
\text { Excellent } \\
6\end{array}$ \\
\hline \multicolumn{7}{|c|}{ Table 2} \\
\hline
\end{tabular}

Many studies have been done on the internal fixation of medial condyle fractures in adults. Our study is comparable to the other studies. Similar to the study of Jupiter et al and Behrman et al Milch type II fractures were more common in our study, which was in contrast to the study by Nagi et al. The most common mechanism of injury was RTA in our study, which was in contrast to other studies where self-fall was more common. Similar to other studies we obtained excellent and good results in all the cases.

\section{CONCLUSION}

Medial condyle fractures are exceptionally rare. Displaced medial condyle fractures must be managed by open reduction and internal fixation. Accurate anatomical reduction to preinjury status, rigid fixation and aggressive physiotherapy is the key to the management. Fixation with cancellous screws, and/or recon-plate is an effective method of rigid fixation to achieve good to excellent results.

\section{REFERENCES}

[1] Kilfoyle RM. Fractures of the medial condyle and epicondyle of the elbow in children. Clin Orthop Relat Res 1965;41:43-50.

[2] Bensahel H, Csukonyi Z, Badelon O, et al. Fractures of the medial condyle of the humerus in children. J Pediatr Orthp 1986;6(4):430-3.

[3] Ghawabi MH. Fracture of the medial condyle of the humerus. J Bone Joint Surg 1975;57(5):677-80.

[4] Aitken GK, Rorabeck CH. Distal humeral fractures in the adult. Clin Orthop Relat Res 1986;207:191-7.

[5] Milch H. Fractures and fracture dislocation of the humeral condyle. J Trauma 1964;4:592-607. 